Cite this: Phys. Chem. Chem. Phys., 2013 15, 14748

Received 23rd May 2013, Accepted 21st July 2013

DOI: $10.1039 / \mathrm{c} 3 \mathrm{cp} 52189 \mathrm{c}$

www.rsc.org/pccp

\title{
Reaction of silylene with sulfur dioxide: some gas-phase kinetic and theoretical studies $\dagger$
}

\author{
Rosa Becerra, ${ }^{\star a}$ J. Pat Cannady, ${ }^{b}$ Nicola Goldberg ${ }^{c}$ and Robin Walsh*c
}

\begin{abstract}
Time-resolved kinetic studies of the reaction of silylene, $\mathrm{SiH}_{2}$, with $\mathrm{SO}_{2}$ have been carried out in the gas phase over the temperature range 297-609 K, using laser flash photolysis to generate and monitor $\mathrm{SiH}_{2}$. The second order rate coefficients at $1.3 \mathrm{kPa}\left(\mathrm{SF}_{6}\right.$ bath gas) fitted the Arrhenius equation: $\log \left(k / \mathrm{cm}^{3}\right.$ molecule $\left.{ }^{-1} \mathrm{~s}^{-1}\right)=(-10.10 \pm 0.06)+\left(3.46 \pm 0.45 \mathrm{~kJ} \mathrm{~mol}^{-1}\right) / R T \ln 10$ where the uncertainties are single standard deviations. The collisional efficiency is $71 \%$ at $298 \mathrm{~K}$, and in kinetic terms the reaction most resembles those of $\mathrm{SiH}_{2}$ with $\mathrm{CH}_{3} \mathrm{CHO}$ and $\left(\mathrm{CH}_{3}\right)_{2} \mathrm{CO}$. Quantum chemical calculations at the $\mathrm{G} 3$ level suggest a mechanism occurring via addition of $\mathrm{SiH}_{2}$ to one of the $\mathrm{S}=\mathrm{O}$ double bonds leading to formation of the three-membered ring, thione-siloxirane which has a low energy barrier to ring expansion to yield the four-membered ring, 3-thia-2,4-dioxasiletane, the lowest energy adduct found on the potential energy (PE) surface. RRKM calculations, however, show that, if formed, this molecule would only be partially stabilised under the reaction conditions and the rate coefficients would be pressure dependent, in contrast with experimental findings. The G3 calculations reveal the complexity of possible intermediates and end products and taken together with the RRKM calculations indicate the most likely end products to be $\mathrm{H}_{2} \mathrm{SiO}+\mathrm{SO}\left({ }^{3} \Sigma^{-}\right)$. The reaction is compared and contrasted with that of $\mathrm{SiH}_{2}+\mathrm{CO}_{2}$.
\end{abstract}

\section{Introduction}

Silylenes are important intermediates in silicon hydride and organosilicon chemistry. ${ }^{1-3}$ Their characteristic reactions include insertions into $\mathrm{Si}-\mathrm{H}, \mathrm{Si}-\mathrm{OR}$ and $\mathrm{O}-\mathrm{H}$ bonds and $\pi$-type additions across $\mathrm{C}=\mathrm{C}$ and $\mathrm{C} \equiv \mathrm{C}$ bonds. Many of the fine details of the mechanisms of these reactions have been revealed by time-resolved kinetic studies employing direct monitoring of silylenes. ${ }^{4-8}$ In recent times, much attention has been devoted to the preparation and properties of large silylenes, stabilised either by bulky substituents, or by being built into N-heterocyclic rings or with N-heterocyclic adducts. ${ }^{9}$ Nevertheless there still remains a need to uncover further details of the behaviour of the smaller, more reactive silylenes to establish a reactivity baseline. In our laboratories we have undertaken gas-phase studies of the

\footnotetext{
${ }^{a}$ Instituto de Quimica-Fisica 'Rocasolano', C.S.I.C., C/Serrano 119, 28006 Madrid, Spain.E-mail: r.becerra@iqfr.csic.es

${ }^{b}$ Dow Corning Corporation, Mail Stop 128, 2200 West Salzburg Road, Midland, Michigan, 48641, USA

${ }^{c}$ School of Chemistry, University of Reading, Whiteknights, P.O. Box 224, Reading, RG6 6AD, UK. E-mail: r.walsh@reading.ac.uk

$\dagger$ Electronic supplementary information (ESI) available: It contains details of the microscopic reversibility relationship, and structures and enthalpies for the quantum chemical calculation of the reaction of $\mathrm{SiH}_{2}$ with $\mathrm{CO}_{2}$ to yield 3-sila2,4-dioxa-cyclobutylidene and other species, at both G3 and G2 levels. See DOI: $10.1039 / \mathrm{c} 3 \mathrm{cp} 52189 \mathrm{c}$
}

prototype silylene, $\mathrm{SiH}_{2} \cdot{ }^{4-6}$ These investigations have shown, inter alia, that it reacts rapidly with many chemical species at close to collision rates. Amongst these are the reactions of $\mathrm{SiH}_{2}$ with $\left(\mathrm{CH}_{3}\right)_{2} \mathrm{CO}^{10}$ and $\mathrm{CH}_{3} \mathrm{CHO}^{11}$ which show that silylene addition to the $\mathrm{C}=\mathrm{O} \pi$-bond conforms to this pattern as well. Even the reaction of $\mathrm{SiH}_{2}$ with $\mathrm{CO}$ is rapid at pressures sufficiently high to stabilize the silaketene product, $\mathrm{H}_{2} \mathrm{SiCO}$, although at normal experimental pressures ( $c a .1 .3 \mathrm{kPa})$ the reaction is quite slow. ${ }^{12}$ We also investigated the reaction of silylene with $\mathrm{CO}_{2}$ showing that the affinity of $\mathrm{SiH}_{2}$ for the carbonyl bond extends even to the highly stable carbon dioxide molecule. ${ }^{13}$ However in this case the reaction is very slow with rate coefficients $10^{4}-10^{5}$ smaller than collisional. This reaction also has a positive activation energy unlike those of most of the others. By means of quantum chemical calculations, ${ }^{13}$ we were able to trace the origin of the reaction bottleneck to the relatively high energy barrier for rearrangement of the initially formed $\mathrm{H}_{2} \mathrm{Si} \cdots \mathrm{O}=\mathrm{C}=\mathrm{O}$ adduct.

Because of the unusual nature of its reaction with $\mathrm{CO}_{2}$ we thought it would be worthwhile to extend our studies of $\mathrm{SiH}_{2}$ to its reaction with $\mathrm{SO}_{2}$. There has been no previous kinetic study of this reaction, so we have undertaken the first gas-phase investigation. As well as being a molecule of considerable atmospheric interest, $\mathrm{SO}_{2}$ differs from $\mathrm{CO}_{2}$ in being bent and having a somewhat weaker double bond. This should have significant consequences on the nature of the products and 
reactive intermediate species. We have therefore also carried out quantum chemical calculations of the potential energy surface for the reaction of $\mathrm{SiH}_{2}+\mathrm{SO}_{2}$, to compare it with that for $\mathrm{SiH}_{2}+\mathrm{CO}_{2}$, and also to try to elucidate potential products and reaction pathways.

\section{Experimental}

\section{Equipment, chemicals and method}

These have been described in detail previously ${ }^{4-6}$ and so only brief and essential details are provided here. $\mathrm{SiH}_{2}$ was produced by the $193 \mathrm{~nm}$ flash photolysis of phenylsilane $\left(\mathrm{PhSiH}_{3}\right)$ using a Coherent Compex 100 exciplex laser. Photolysis pulses were fired into a variable temperature quartz reaction vessel with demountable windows, at right angles to its main axis. $\mathrm{SiH}_{2}$ concentrations were monitored in real time by means of a Coherent 699-21 single-mode dye laser pumped by an Innova 90-5 argon ion laser and operating with Rhodamine 6G. The monitoring laser beam was multipassed between 32 and 40 times along the vessel axis, through the reaction zone, to give an effective path length of up to $1.6 \mathrm{~m}$. A portion of the monitoring beam was split off before entering the vessel for reference purposes. The laser wavelength was set by reference to a known coincident transition in the visible spectrum of $\mathrm{I}_{2}$ vapour and was checked at frequent intervals during the experiments. For $\mathrm{SiH}_{2}$ detection, the monitoring laser was tuned to $17259.50 \mathrm{~cm}^{-1}$, corresponding to a known strong ${ }^{\mathrm{R}} \mathrm{Q}_{0, \mathrm{~J}}(5)$ vibration-rotation transition ${ }^{14}$ in the $\tilde{A}^{1} \mathrm{~B}_{1}(0,2,0) \leftarrow$ $\tilde{X}^{1} \mathrm{~A}_{1}(0,0,0)$ vibronic absorption band. Light signals were measured by a dual photodiode-differential amplifier combination and signal decays were stored in a transient recorder (Datalab DL910) interfaced to a BBC microcomputer. This was used to average the decays of between 5 and 20 photolysis laser shots (at a repetition rate of 0.5 or $1 \mathrm{~Hz}$ ). The averaged decay traces were processed by fitting the data to an exponential form using a non-linear least squares package. This analysis provided the values for first-order rate coefficients, $k_{\text {obs }}$, for removal of $\mathrm{SiH}_{2}$ in the presence of known partial pressures of substrate gas. Static gas mixtures were used and the optics were cleaned regularly.

Gas mixtures for photolysis were made up, containing between 0.19 and $0.5 \mathrm{~Pa}$ of $\mathrm{PhSiH}_{3}$, a few $\mathrm{Pa}$ of $\mathrm{SO}_{2}$ and inert diluent $\left(\mathrm{SF}_{6}\right)$ at added pressures of between 0 and $13 \mathrm{kPa}$. For each series of experiments the pressures of $\mathrm{SO}_{2}$ were in the range: 0-10.6 Pa. The majority of experiments were performed at a total pressure of $1.3 \mathrm{kPa}$. Pressures were measured by capacitance manometers (MKS, Baratron).

All gases used in this work were frozen at $77 \mathrm{~K}$ and pumped free of any vestiges of air prior to use. $\mathrm{PhSiH}_{3}(99.9 \%)$ was obtained from Ventron-Alfa (Petrarch). $\mathrm{SO}_{2}$ (99.9+\%) was from Aldrich. Sulfur hexafluoride, $\mathrm{SF}_{6}$, (no GC-detectable impurities) was from Cambrian Gases.

\section{$A b$ initio calculations}

The electronic structure calculations were performed initially with the Gaussian 98 and subsequently the Gaussian 03 software packages. ${ }^{15}$ All structures were determined by energy minimization at the MP2 = full/6-31G(d) level. Transition state structures were characterised as first order saddle points by calculation of the hessian matrix. Stable structures, corresponding to energy minima, were identified by possessing no negative eigenvalues of the Hessian, whilst transition states were identified by having one and only one negative eigenvalue. The standard Gaussian-3 (G3) compound method ${ }^{16}$ was employed to determine final energies for all local minima. For transition states the elements of the G3 method were used, viz: optimization to TS at $\mathrm{HF} / 6-31 \mathrm{G}(\mathrm{d})$, frequencies at $\mathrm{HF} / 6-31 \mathrm{G}(\mathrm{d})$, optimization to TS at MP2 = full/6-31G(d), followed by four single point energy determinations at the MP2 = full/6-31G(d) geometry, viz.: QCISD(T)/6-31G(d), MP4/6-31+G(d), MP4/6-31G(2df,p), and MP2 $=$ full/G3 large, and the values were combined according to the G3 procedure. ${ }^{16}$ The identities of the transition state structures were verified by calculation of Intrinsic Reaction Co-ordinates ${ }^{17}$ (IRC) at the MP2 = full/6-31G(d) level. Reaction barriers were calculated as differences in G3 enthalpies at 298.15 K (quoted simply as $\Delta H$ in the tables and figures of results). Wavenumbers for harmonic vibrations, needed for Rice, Ramsperger, Kassel, Marcus (RRKM) calculations, were obtained by adjustment of the values given by the calculations, using correction factor, $0.893 .^{18}$

\section{Results}

\section{Kinetic measurements}

It was independently verified during preliminary experiments that, in a given reaction mixture, $k_{\mathrm{obs}}$ values were not dependent on the exciplex laser energy or number of photolysis shots. This is especially important because $\mathrm{SO}_{2}$ is known to absorb $193 \mathrm{~nm}$ radiation and undergo photodissociation. ${ }^{19}$ Because static gas mixtures were used, tests with up to 10 shots were carried out. The constancy of $k_{\text {obs }}$ (5 shot averages) showed no effective depletion of reactants (especially of $\mathrm{SO}_{2}$ ). The lack of dependence of $k_{\text {obs }}$ on exciplex laser energy showed the unlikelihood of perturbation of the decay by additional reaction of $\mathrm{SiH}_{2}$ with a photoproduct (such as SO). The sensitivity of detection of $\mathrm{SiH}_{2}$ was high but decreased with increasing temperature. Therefore increasing quantities of precursor were required at higher temperatures. However, at any given temperature precursor pressures were kept fixed to ensure a constant (but always small) contribution to $k_{\text {obs }}$ values.

A series of experiments was carried out at five temperatures in the range $297-609 \mathrm{~K}$ at total pressures of $1.3 \mathrm{kPa}$. At each temperature, a number of runs (at least seven) at different $\mathrm{SO}_{2}$ partial pressures were carried out. The results of these experiments are shown in Fig. 1, which demonstrates the linear dependence of $k_{\mathrm{obs}}$ on $\left[\mathrm{SO}_{2}\right]$, as expected for second-order kinetics. The second order rate coefficients, $k$, obtained by least-squares fitting to these plots, are given in Table 1 . The error limits are single standard deviations. A few experiments at different total pressures up to $13 \mathrm{kPa}$ (of added $\mathrm{SF}_{6}$ ) were also carried out. In these experiments only two or three runs with different partial pressures of $\mathrm{SO}_{2}$ were undertaken and second order kinetics was assumed. The rate coefficients from these experiments, inevitably with larger uncertainties, are also given in Table 1. It can be seen that there is a slight pressure dependence 


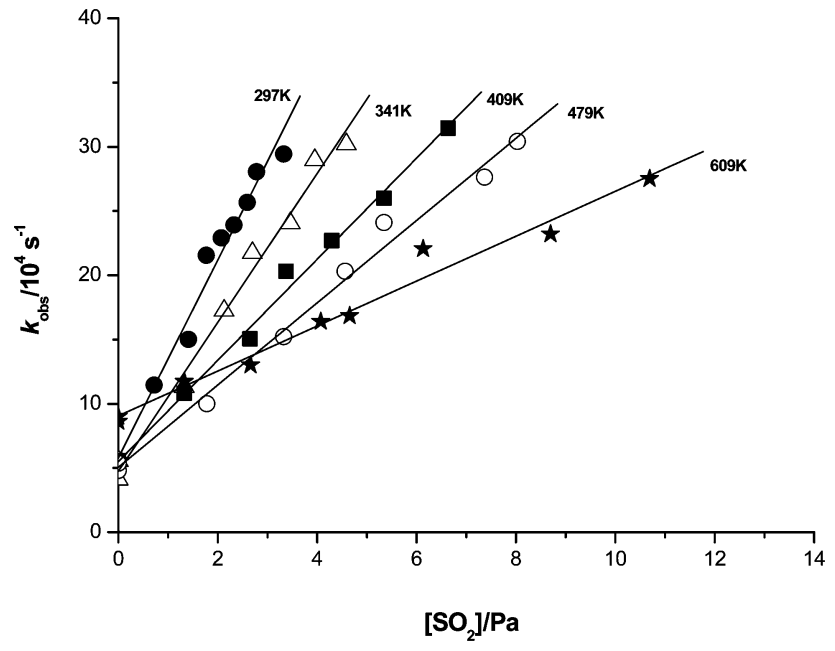

Fig. 1 Second order plots for reaction of $\mathrm{SiH}_{2}$ with $\mathrm{SO}_{2}$ at various temperatures (indicated). Different symbols are used at the each temperature.

Table 1 Experimental second order rate coefficients ${ }^{a}$ for $\mathrm{SiH}_{2}+\mathrm{SO}_{2}$

Pressure/kPa

\begin{tabular}{llllll}
\cline { 2 - 6 }$T / \mathrm{K}$ & 0.13 & 0.40 & 1.3 & 4.0 & 13 \\
\hline 297 & $2.53 \pm 0.23$ & $3.21 \pm 0.26$ & $3.15 \pm 0.15$ & $3.38 \pm 0.33$ & $3.66 \pm 0.24$ \\
341 & $2.40 \pm 0.17$ & $2.50 \pm 0.17$ & $2.72 \pm 0.09$ & $2.92 \pm 0.17$ & $3.12 \pm 0.68$ \\
409 & $1.85 \pm 0.13$ & $2.24 \pm 0.23$ & $2.22 \pm 0.05$ & $2.16 \pm 0.13$ & $2.93 \pm 0.01$ \\
479 & $1.46 \pm 0.03$ & $1.61 \pm 0.17$ & $2.10 \pm 0.07$ & $1.92 \pm 0.05$ & $2.31 \pm 0.06$ \\
609 & $1.12 \pm 0.02$ & $1.26 \pm 0.09$ & $1.47 \pm 0.08$ & $1.48 \pm 0.06$ & $1.57 \pm 0.15$ \\
${ }^{a}$ Units: $10^{-10} \mathrm{~cm}^{3}$ molecule ${ }^{-1} \mathrm{~s}^{-1}$. & & \\
\hline
\end{tabular}

of the rate coefficients, although within the error limits, they are close to pressure independent.

An Arrhenius plot of $k$ (at $1.3 \mathrm{kPa}$ ) is shown in Fig. 2. The data correspond to the following equation:

$$
\begin{aligned}
\log \left(k / \mathrm{cm}^{3}\right. \text { molecule } & -1 \\
\left.\mathrm{~s}^{-1}\right)= & (-10.10 \pm 0.06) \\
& +(3.46 \pm 0.45) \mathrm{kJ} \mathrm{mol}^{-1} / R T \ln 10
\end{aligned}
$$

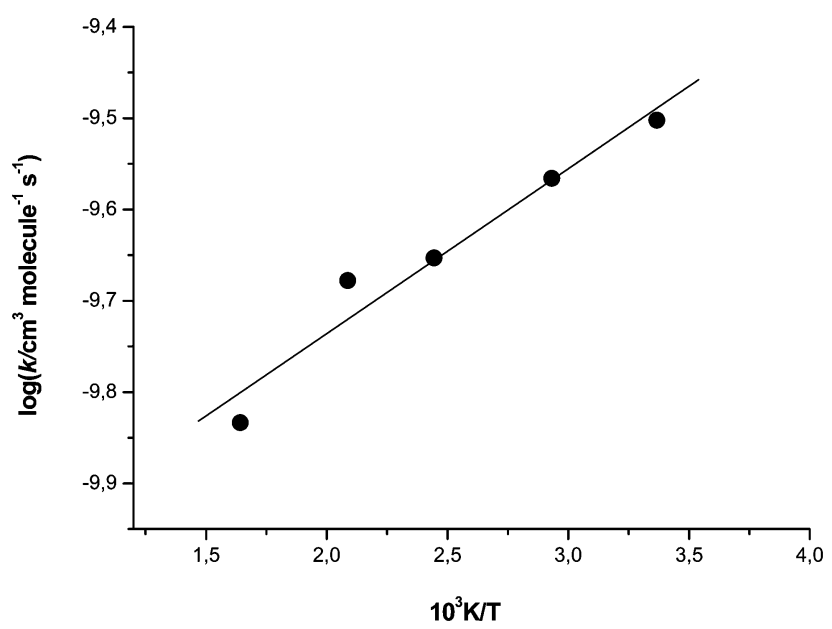

Fig. 2 Arrhenius plot of rate coefficients for reaction of $\mathrm{SiH}_{2}$ with $\mathrm{SO}_{2}$.

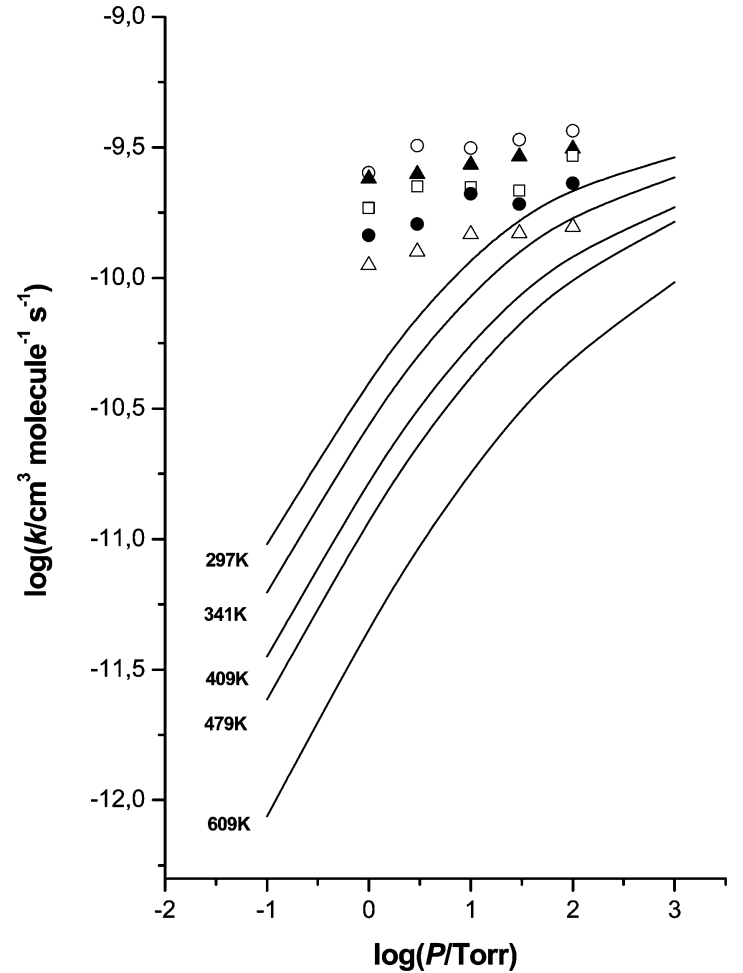

Fig. 3 Pressure dependence of second order rate coefficients for $\mathrm{SiH}_{2}+\mathrm{SO}_{2}$ at different temperatures/K: $O, 297 ; \mathbf{\Lambda}, 341 ; \square, 409 ; \bullet, 479 ; \triangle, 609$. Solid lines are RRKM theoretical fits at each temperature. NB 1 Torr $=133.2 \mathrm{~Pa}$.

Fig. 3 shows the pressure dependence of $k$ together with the results of RRKM calculations (see later), presented in a log-log plot for convenience.

\section{Quantum chemical (ab initio) calculations}

Apart from the reactant species, $\mathrm{SiH}_{2}+\mathrm{SO}_{2}, 17$ other minima and 12 transition states (TS1-11) were found in these calculations. The minima comprised three molecular complexes $\left(\mathrm{H}_{2} \mathrm{Si} \cdots \mathrm{OSO}\right.$, $\mathrm{H}_{2} \mathrm{SiO} \cdots{ }^{1} \mathrm{SO}$ and $\left.\mathrm{H}_{2} \mathrm{SiO} \cdots{ }^{3} \mathrm{SO}\right),{ }^{20}$ three possible molecular product pairs $\left(\mathrm{H}_{2} \mathrm{SiO}+{ }^{1} \mathrm{SO}, \mathrm{H}_{2} \mathrm{SiO}+{ }^{3} \mathrm{SO}\right.$ and $\left.\mathrm{SiO}_{2}+\mathrm{H}_{2} \mathrm{~S}\right)$, four possible radical pairs $(\mathrm{HSiO}+\mathrm{HSO}, \mathrm{HSiO}+\mathrm{HOS}, \mathrm{HSiOS}+\mathrm{OH}$ and $\mathrm{HOSi}=\mathrm{O}+\mathrm{SH}$ ) and 7 single molecular species (cyclo$\mathrm{H}_{2} \mathrm{SiS}(=\mathrm{O}) \mathrm{O}-$, cyclo- $\mathrm{H}_{2} \mathrm{SiOSO}-, \mathrm{H}_{2} \mathrm{SiOS}=\mathrm{O}(\mathrm{i}), \mathrm{H}_{2} \mathrm{SiOS}=\mathrm{O}(\mathrm{ii})$, $\mathrm{HSiOS}(\mathrm{H})=\mathrm{O}, \mathrm{HSiOSOH}$ and cyclo-HSiOSHO-) two of which, thione-siloxirane (cyclo- $\mathrm{H}_{2} \mathrm{SiS}(=\mathrm{O}) \mathrm{O}-$ ) and 3-thia-2,4-dioxasiletane (cyclo- $\mathrm{H}_{2} \mathrm{SiOSO}-$ ), three and four membered rings respectively, are potential molecular end products. The minima and transition states linking these species are shown on the PES in Fig. 4. Not included in the figure are HSiOS $+\mathrm{OH}$ because it is too high in energy to be accessible and TS11, which is a transition state between two conformers of $\mathrm{H}_{2} \mathrm{SiO} \ldots{ }^{1} \mathrm{SO}$. The links from $\mathrm{HSiOS}(\mathrm{H})=\mathrm{O}$ and $\mathrm{HSiOSOH}$ corresponding to dissociation pathways to $\mathrm{HSiO}+\mathrm{HSO}$ and $\mathrm{HSiO}+\mathrm{HOS}$ respectively, are only shown partially in order to avoid cluttering the diagram. These radical pairs are only marginally endothermic relative to $\mathrm{SiH}_{2}+\mathrm{SO}_{2}$, and so are included in the surface. Total enthalpies (at $298 \mathrm{~K}$ ) and enthalpy values for all structures 


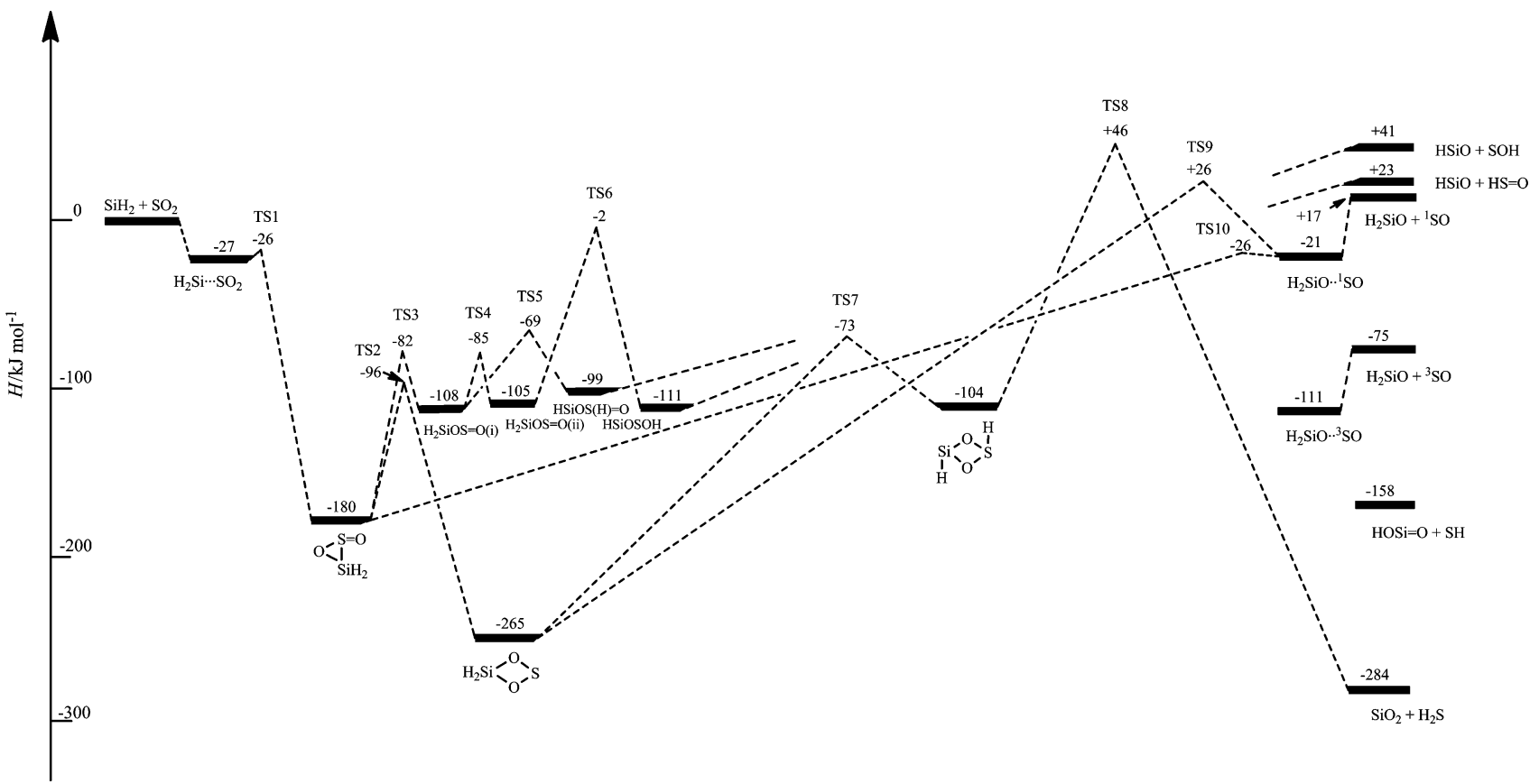

Fig. 4 Potential energy (enthalpy) surface for the reaction of $\mathrm{SiH}_{2}+\mathrm{SO}_{2}$. All enthalpies are calculated at the $\mathrm{G} 3$ level and quoted at $298 \mathrm{~K}$.

relative to $\mathrm{SiH}_{2}+\mathrm{SO}_{2}$ are listed in Table 2. The structures of all these species are shown in Fig. 5-7.

G3 calculations were attempted on all species which appeared reasonable to us, although not all conceivable radical pairs (e.g. $\mathrm{HSSi}=\mathrm{O}+\mathrm{OH})$ were considered. Moreover, pathways to some possible radical pairs (e.g. $\mathrm{HOSi}=\mathrm{O}+\mathrm{SH})$, despite being exothermic with respect to reactants, were not considered because the bonding rearrangements required to produce them appear too complicated to be plausible. One exception to this, which illustrates this difficulty, was the stable product pair $\mathrm{SiO}_{2}+\mathrm{H}_{2} \mathrm{~S}$. While these are the lowest energy products of the whole system, the pathway to them requires passage via TS8, with a positive enthalpy of $46 \mathrm{~kJ} \mathrm{~mol}^{-1}$. If this pathway were to occur, the overall reaction would have a substantially positive activation energy.

The surface indicates that the reaction proceeds by the initial formation of the weakly bound $\mathrm{H}_{2} \mathrm{Si}$. OSO complex. Brief attempts were made to explore the possibility of formation of the $\mathrm{Si} \cdots \mathrm{S}$ bonded species, $\mathrm{H}_{2} \mathrm{Si} \cdots \mathrm{S}(\mathrm{O})=\mathrm{O}$, but such a species could not be found. $\mathrm{H}_{2} \mathrm{Si}$. OSO reacts readily by a cyclisation process to the 3-membered thione-siloxirane ring via TS1. This ring exists in a fairly deep enthalpy well $\left(-180 \mathrm{~kJ} \mathrm{~mol}^{-1}\right)$. Further reaction can now take place in three possible ways. The first, but least likely (due to its overall endothermicity), is a dissociation process into $\mathrm{H}_{2} \mathrm{Si}=\mathrm{O}+{ }^{1} \mathrm{~S}=\mathrm{O}$ via TS9 and a weakly bound predissociation complex. The second and most likely is ring expansion to the 4-membered 3-thia-2,4-dioxa-siletane ring, via TS2 (-96 $\left.\mathrm{kJ} \mathrm{mol}^{-1}\right)$. This 4-membered ring is the most stable single molecular species found in this system (with a relative enthalpy of $-265 \mathrm{~kJ} \mathrm{~mol}^{-1}$ ). Its formation appears to proceed only via the 3 -membered ring. The third pathway which is endothermic but has a barrier, TS3 $\left(-82 \mathrm{~kJ} \mathrm{~mol}^{-1}\right)$, only marginally higher than TS2, involves ring opening of the Si-S
Table $2 \mathrm{G}^{a}$ calculated total enthalpies, $\mathrm{H} / \mathrm{H}$ artree, and relative enthalpies, $\Delta H_{\text {rel }} / \mathrm{kJ} \mathrm{mol}^{-1}$, for stationary points of interest on the $\mathrm{H}_{2} \mathrm{SiSO}_{2}$ energy surface

\begin{tabular}{|c|c|c|}
\hline Species & $H(298 \mathrm{~K}) / \mathrm{Ha}$ & $\Delta H_{\mathrm{rel}} / \mathrm{kJ} \mathrm{mol}^{-1}$ \\
\hline $\begin{array}{l}\mathrm{SiH}_{2}+\mathrm{SO}_{2} \\
\mathrm{H}_{2} \mathrm{Si} \cdots \text { OSO complex }\end{array}$ & $\begin{array}{l}-838.871430 \\
-838.881596\end{array}$ & $\begin{array}{r}0 \\
-27\end{array}$ \\
\hline $\mathrm{O}_{\substack{-\mathrm{S}=\mathrm{O} \\
\mathrm{SiH}_{2}}}^{\mathrm{I}}$ & -838.940020 & -180 \\
\hline $\mathrm{H}_{2} \mathrm{Si}^{\prime} \div \mathrm{O}^{\prime} \mathrm{S}$ & -838.972484 & -265 \\
\hline $\begin{array}{l}\mathrm{H}_{2} \mathrm{SiOS}=\mathrm{O} \text { adduct(i) } \\
\mathrm{H}_{2} \mathrm{SiOS}=\mathrm{O} \text { adduct(ii) } \\
\mathrm{HSiOS}(\mathrm{H})=\mathrm{O} \\
\mathrm{HSiOSOH}\end{array}$ & $\begin{array}{l}-838.912578 \\
-838.911499 \\
-838.909122 \\
-838.913520\end{array}$ & $\begin{array}{r}-108 \\
-105 \\
-99 \\
-111\end{array}$ \\
\hline O'sH & -838.911133 & -104 \\
\hline $\mathrm{H}_{2} \mathrm{SiO} \cdots \mathrm{S}=\mathrm{O}$ complex (singlet) & -838.879625 & -22 \\
\hline $\mathrm{H}_{2} \mathrm{SiO}+{ }^{1} \mathrm{~S}=\mathrm{O}$ & -838.864886 & +17 \\
\hline $\mathrm{H}_{2} \mathrm{SiO} \cdots \mathrm{S}=\mathrm{O}$ complex (triplet) & -838.913721 & -111 \\
\hline $\mathrm{H}_{2} \mathrm{SiO}+{ }^{3} \mathrm{~S}=\mathrm{O}$ & -838.900142 & -75 \\
\hline $\mathrm{SiO}_{2}+\mathrm{H}_{2} \mathrm{~S}$ & -838.979428 & -284 \\
\hline $\mathrm{HSi}=\mathrm{O}+\mathrm{HS}=\mathrm{O}$ & -838.862696 & +23 \\
\hline $\mathrm{HSi}=\mathrm{O}+\mathrm{HOS}$ & -838.855714 & +41 \\
\hline $\mathrm{HSiOS}+\mathrm{OH}$ & -838.800711 & +186 \\
\hline $\mathrm{HOSi}=\mathrm{O}+\mathrm{SH}$ & -838.931688 & -158 \\
\hline TS1 & -838.881213 & -26 \\
\hline TS2 & -838.908149 & -96 \\
\hline TS3 & -838.902757 & -82 \\
\hline TS4a & -838.903787 & -85 \\
\hline TS4b & -838.903742 & -85 \\
\hline TS5 & -838.897894 & -69 \\
\hline TS6 & -838.872222 & -2 \\
\hline TS7 & -838.899076 & -73 \\
\hline TS8 & -838.853934 & +46 \\
\hline TS9 & -838.861368 & +26 \\
\hline TS10 & -838.881197 & -26 \\
\hline TS11 & -838.876278 & -13 \\
\hline
\end{tabular}

${ }^{a}$ Full expression: G3//MP2 = full/6-31G(d). 


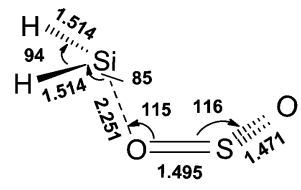

$\mathrm{H}_{2} \mathrm{Si} \cdots \mathrm{OSO}$ complex

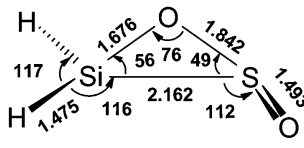

thione-siloxirane

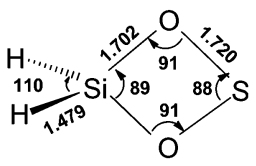

3-thia-2,4-dioxa-siletane

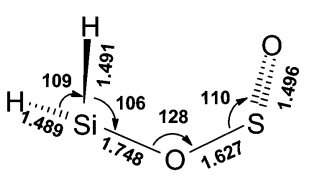

Adduct (i)

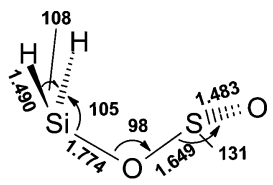

Adduct (ii)

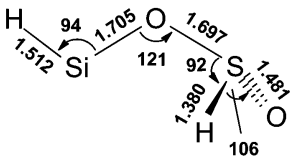

$\operatorname{HSiOS}(\mathrm{H})=0$

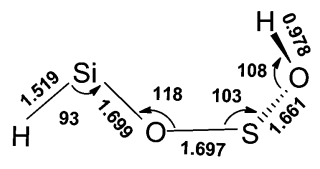

HSiOSOH

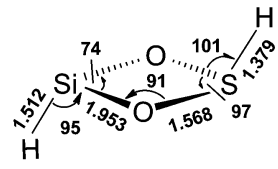

cyclo-HSiOOSH

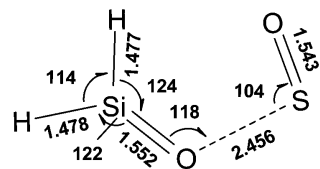

$\mathrm{H}_{2} \mathrm{SiO} \cdots \mathrm{S}=\mathrm{O}$ complex(singlet)

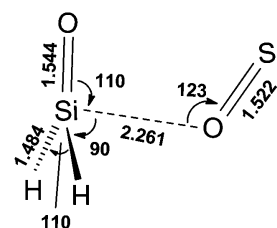

$\mathrm{H}_{2} \mathrm{SiO} \cdots \mathrm{S}=\mathrm{O}$ complex(triplet)

Fig. 5 Quantum chemical, MP2 = full/6-31G(d) calculated geometries of single molecular species on the $\mathrm{SiH}_{2}+\mathrm{SO}_{2}$ potential energy surface. Bond lengths are in $\AA$ and angles in degrees.

bond to form a silylene sulfur dioxide adduct, $\mathrm{H}_{2} \mathrm{SiOS}=\mathrm{O}(\mathrm{i})$. This adduct and its conformational partner, $\mathrm{H}_{2} \mathrm{SiOS}=\mathrm{O}(\mathrm{ii})$, have the same molecular linkages as the initial complex, $\mathrm{H}_{2} \mathrm{Si}$. OSO but differ from it in having clearly defined $\mathrm{Si}-\mathrm{O}$ and O-S single bonds which render both adducts more stable than the complex. $\mathrm{H}_{2} \mathrm{SiOS}=\mathrm{O}$ (i) and $\mathrm{H}_{2} \mathrm{SiOS}=\mathrm{O}$ (ii) only differ in enthalpy from one another by $3 \mathrm{~kJ} \mathrm{~mol}^{-1}$ and are readily interconverted by rotations around the single bonds via TS4a which lies only $23 \mathrm{~kJ} \mathrm{~mol}^{-1}$ above $\mathrm{H}_{2} \mathrm{SiOS}=\mathrm{O}(\mathrm{i})$. Another transition state, TS4b, was found with the same enthalpy value but with a linear $\mathrm{Si}-\mathrm{O}-\mathrm{S}$ configuration, indicating that interconversion via angle bending is also possible. Clearly the adducts are pretty labile species. In the light of these easy interconversions other possible conformers were searched for. None was found. It should be noted that possible routes from the initial complex directly to these adducts, which are exothermic, would appear to require only rather small changes in bond length and conformation. Nevertheless no such routes were found and the IRC pathway from TS1 to cyclo- $\mathrm{H}_{2} \mathrm{SiS}(=\mathrm{O}) \mathrm{O}-$ was not diverted into either of the adducts.
It appears that adduct(i) can only be formed via the thionesiloxirane ring, and adduct(ii) only from adduct(i).

Since all the single molecular species reached thus far are substantially exothermic relative to reactants, $\mathrm{SiH}_{2}+\mathrm{SO}_{2}$, further sequential processes across the reaction surface need to be considered. These may proceed from either the four-membered ring or one or both of the adducts. Pathways from 3-thia-2,4-dioxasiletane are considered first. This has an endothermic route to $\mathrm{H}_{2} \mathrm{Si}=\mathrm{O}+{ }^{1} \mathrm{~S}=\mathrm{O}$ via TS9 and the $\mathrm{H}_{2} \mathrm{Si}=\mathrm{O} \cdots{ }^{1} \mathrm{~S}=\mathrm{O}$ predissociation complex. As well as $\mathrm{H}_{2} \mathrm{Si}=\mathrm{O}+{ }^{1} \mathrm{~S}=\mathrm{O}$, TS9 lies above the reactant's enthalpy, making this pathway doubly unviable. An alternative decomposition route for 3-thia-2,4-dioxa-siletane, requires the double $\mathrm{H}$-atom transfer from $\mathrm{Si}$ to $\mathrm{S}$ across the ring. The first step generates the new 4-membered ring, cyclo-HSiOSHO-, $\left(-104 \mathrm{~kJ} \mathrm{~mol}^{-1}\right)$ via TS7 $\left(-73 \mathrm{~kJ} \mathrm{~mol}^{-1}\right)$, but the second step via TS8 $\left(+46 \mathrm{~kJ} \mathrm{~mol}^{-1}\right)$, is too high in enthalpy to permit this pathway leading to $\mathrm{SiO}_{2}+\mathrm{H}_{2} \mathrm{~S}$, as mentioned above.

Starting from adducts (i) or (ii), dissociation to $\mathrm{H}_{2} \mathrm{SiO}+{ }^{1} \mathrm{SO}$ either directly or via the predissociation complex, might appear 


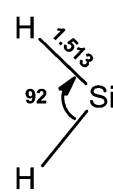

$\mathrm{SiH}_{2}$<smiles></smiles>

$\mathrm{SO}_{2}$<smiles>[CH]1[CH]C=C1</smiles>

$\mathrm{H}_{2} \mathrm{~S}$
$S \stackrel{1.344}{H}$

HS
$\mathrm{O} \stackrel{0.979}{\mathrm{H}}$

$\mathrm{OH}$

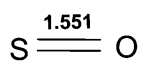

So singlet
$S \stackrel{1.524}{=} \mathrm{O}$

So triplet
$\mathrm{O} \stackrel{1.531}{=} \mathrm{Si}=\mathrm{O}$

$\mathrm{SiO}_{2}$

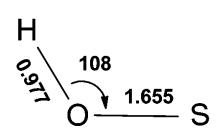

HOS

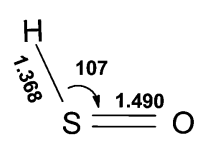

HSO

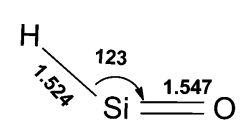

HSiO

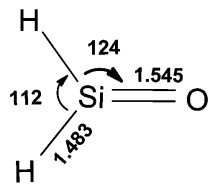

$\mathrm{H}_{2} \mathrm{SiO}$

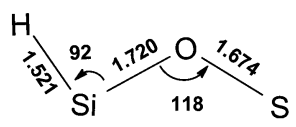

HSiOS

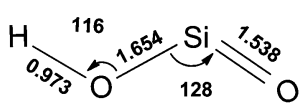

HOSiO

Fig. 6 Quantum chemical, MP2 = full/6-31G(d) calculated geometries of small molecular fragment species on the $\mathrm{SiH}_{2}+\mathrm{SO}_{2}$ potential energy surface. Bond lengths are in $\AA$ and angles in degrees.

as attractive possibilities. Although we searched for these, we could find no such pathways. Also searched for were potential transition states for direct formation of 3-thia-2,4-dioxa-siletane from adducts (i) or (ii). Despite the apparent simplicity of a 1,4 Si to O ring closure, no such transition states were found. However pathways involving $\mathrm{H}$-atom migration were found. From $\mathrm{H}_{2} \mathrm{SiOS}=\mathrm{O}(\mathrm{i}), 1,3 \mathrm{H}$-migration from $\mathrm{Si}$ to $\mathrm{S}$ leads to $\mathrm{HSiOS}(\mathrm{H})=\mathrm{O}$ via TS5 at an enthalpy $69 \mathrm{~kJ} \mathrm{~mol}^{-1}$ below that of the reactants and from $\mathrm{H}_{2} \mathrm{SiOS}=\mathrm{O}(\mathrm{ii})$, 1,4 $\mathrm{H}$-migration from $\mathrm{Si}$ to $\mathrm{O}$ leads to $\mathrm{HSiOSOH}$ via TS6 at an enthalpy only $2 \mathrm{~kJ} \mathrm{~mol}^{-1}$ below that of the reactants. From a kinetic point of view, if H-migration is important at all, formation of $\mathrm{HSiOS}(\mathrm{H})=\mathrm{O}$ would seem more likely. While these H-atom migrations are fairly close to thermoneutral, in fact $\mathrm{HSiOSOH}$ is $6 \mathrm{~kJ} \mathrm{~mol}^{-1}$ exothermic with respect to $\mathrm{H}_{2} \mathrm{SiOS}=\mathrm{O}(\mathrm{ii})$ while $\mathrm{HSiOS}(\mathrm{H})=\mathrm{O}$ is $9 \mathrm{~kJ} \mathrm{~mol}^{-1}$ endothermic relative to $\mathrm{H}_{2} \mathrm{SiOS}=\mathrm{O}(\mathrm{i})$. It is worth noting that both these H-migration products are silylenes. A final question concerning these species is whether they possess plausible dissociation pathways. HSiOSOH might seem capable of breaking the relatively weak $\mathrm{S}-\mathrm{O}$ bonds to yield either $\mathrm{HSiO}+\mathrm{SOH}$, or $\mathrm{HSiOS}+$ $\mathrm{OH}$. Similarly $\mathrm{HSiOS}(\mathrm{H})=\mathrm{O}$ could break its $\mathrm{S}-\mathrm{O}$ bond to produce $\mathrm{HSiO}+\mathrm{HS}=\mathrm{O}$. The calculations show that all these processes form product pairs which are endothermic with respect to the reactants, $\mathrm{SiH}_{2}+\mathrm{SO}_{2}$, thus making them highly unlikely.

All of the above described pathways across this complex reaction landscape occur on the singlet state surface. But the ground state of sulfur monoxide, $\mathrm{S}=\mathrm{O}$ is ${ }^{3} \Sigma^{-}$(ref. 20) and the product pair $\mathrm{H}_{2} \mathrm{SiO}+{ }^{3} \mathrm{SO}$, in contrast to $\mathrm{H}_{2} \mathrm{SiO}+{ }^{1} \mathrm{SO}$, is exothermic with respect to reactants. Thus an attractive mechanistic pathway across this enthalpy surface would be one in which an intersystem crossing occurs at some stage before final formation of $\mathrm{H}_{2} \mathrm{SiO}+{ }^{3} \mathrm{SO}$. Despite a brief search, we have not been able to identify such a pathway.

\section{RRKM calculations}

The pressure dependence of an association reaction corresponds exactly to that of the reverse unimolecular dissociation 


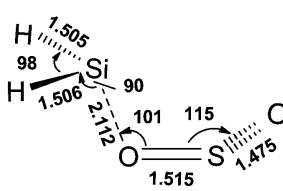

TS1

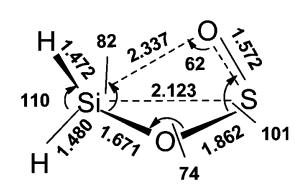

TS2

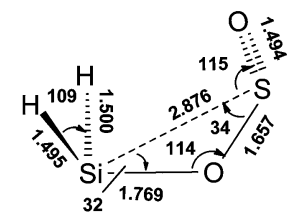

TS3
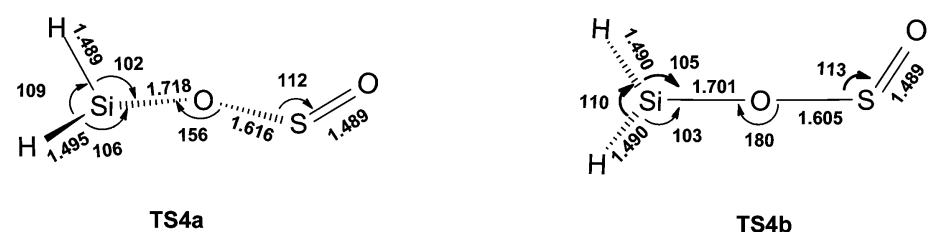

TS4b

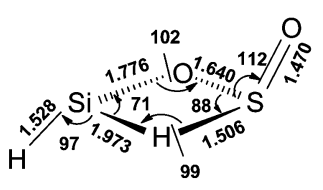

TS5

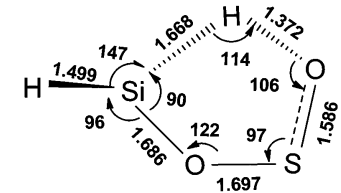

TS6

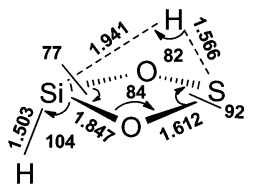

TS7

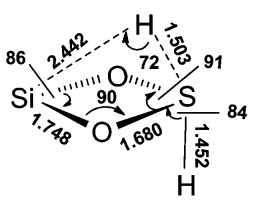

TS8

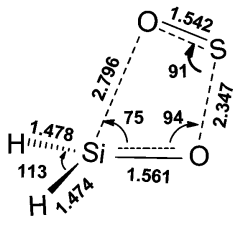

TS9

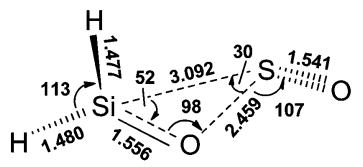

TS10

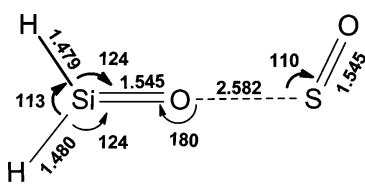

TS11

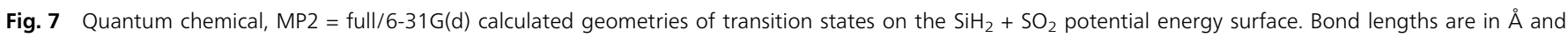
angles in degrees.

process providing there are no other perturbing reaction channels. Although the detailed quantum chemical calculations for $\mathrm{SiH}_{2}+\mathrm{SO}_{2}$ suggest the possibility of several possible channels a strong candidate is the pathway leading to 3-thia-2,4-dioxasiletane (reaction (1)). Analogous association pathways leading to cyclic products exist for the reactions of $\mathrm{SiH}_{2}$ with $\mathrm{C}_{2} \mathrm{H}_{2},{ }^{21}$ $\mathrm{C}_{2} \mathrm{H}_{4},{ }^{22} \mathrm{CH}_{3} \mathrm{CHO}^{11}$ and $\left(\mathrm{CH}_{3}\right)_{2} \mathrm{CO}^{10}$ amongst others. ${ }^{6}$ These reactions all possess pressure dependent rate constants, but the extent of pressure dependence varies and depends on the particular molecular parameters of each reaction. Although any pressure dependence of the rate constants for $\mathrm{SiH}_{2}+\mathrm{SO}_{2}$ is only very slight at most, the quantum chemical calculations provide us with enough information to probe the question of whether such a pressure-dependence should be expected. We have therefore carried out RRKM calculations ${ }^{23}$ on the unimolecular dissociation process of 3-thia-2,4-dioxa-siletane viz:

$$
\text { cyclo- } \mathrm{H}_{2} \mathrm{SiOSO}-\rightarrow \mathrm{H}_{2} \mathrm{Si}+\mathrm{SO}_{2}
$$

3-thia-2,4-dioxa-siletane has never been isolated or studied experimentally and so we are reliant on the quantum chemical calculations to provide the necessary parameters for these calculations. This has been done as follows. First the likely Arrhenius $A$ factors for these decomposition reactions were 
Table 3 Standard entropy changes ${ }^{a}$ and decomposition $A$ factors for 3-thia-2,4dioxa-siletane

\begin{tabular}{|c|c|c|c|c|c|}
\hline \multirow[b]{2}{*}{ Quantity } & \multicolumn{5}{|l|}{$\underline{T / \mathrm{K}}$} \\
\hline & 297 & 341 & 409 & 479 & 609 \\
\hline$\Delta S^{0 b, c}$ & 162.9 & 161.9 & 159.8 & 157.3 & 152.9 \\
\hline $\log \left(A_{-1} / \mathrm{s}^{-1}\right)$ & 17.37 & 17.26 & 17.07 & 16.87 & 16.53 \\
\hline
\end{tabular}

estimated (at each temperature) by use of the microscopic reversibility relationship, $\ln \left(A_{-1} / A_{1}\right)=\Delta S_{-1,1}^{0} / R$ where $A_{-1}$ and $A_{1}$ are the decomposition and association $A$ factors (i.e. $A_{-1}$ is what is required and $A_{1}$ is the experimental value measured here) and $\Delta S_{-1,1}^{0}$ is the entropy change. ${ }^{24}$ The values for $\Delta S_{-1,1}^{0}$ were obtained from the thermodynamic output of the theoretical calculations, although because of the approximations used in the procedure, they were corrected for the vibrational wavenumber factor (0.893). The entropy changes and calculated $A$ factors are shown in Table 3. These were now used to assist in the assignment of vibrational wavenumbers for the transition state, based closely on those of the loose association complex, $\mathrm{H}_{2} \mathrm{Si} \cdots$ OSO, but modified by adjustment of the key transitional mode values leading to dissociation, using the standard Transition State Theory formula, $A=(e k T / h) \exp \left(\Delta S^{\ddagger} / R\right)$. Whether precise values of all vibrational wavenumbers are correct or not is not important provided the entropies of activation, i.e. values of $\Delta S^{\ddagger}$, are matched. The assignment of both molecule and transition state, for decomposition of 3-thia-2,4-dioxa-siletane at $297 \mathrm{~K}$, is shown in Table 4 which also includes the Lennard-Jones collision number value. The assignments at other temperatures are shown in Table 5. The value for the critical energy, $E_{0}$, $\left(259 \mathrm{~kJ} \mathrm{~mol}^{-1}\right)$ employed in these calculations was that given by the quantum chemical calculations (corresponding to $\Delta H=-265 \mathrm{~kJ} \mathrm{~mol}^{-1}$, Table 2). We have used a weak collisional (stepladder) model for collisional deactivation, because there is overwhelming evidence against the strong collision assumption..$^{25}$ The average energy removal parameter, $\langle\Delta E\rangle_{\text {down }}$ for $\mathrm{SF}_{6}$ bath gas, was taken as $12.0 \mathrm{~kJ} \mathrm{~mol}^{-1}\left(1000 \mathrm{~cm}^{-1}\right)$ as used previously for many such reactions. ${ }^{6}$ The results of these calculations are shown in Fig. 3 as pressure dependent "fall-off" curves

Table 4 Molecular and transition state parameters for RRKM calculations for decomposition of 3-thia-2,4-dioxa-siletane at $297 \mathrm{~K}$

\begin{tabular}{|c|c|c|}
\hline Parameter & Molecule & TS $(297 \mathrm{~K})$ \\
\hline \multirow[t]{11}{*}{ Wavenumbers $/ \mathrm{cm}^{-1}$} & $2190(2)$ & $1976(2)$ \\
\hline & 1000 & 1401 \\
\hline & 897 & 1214 \\
\hline & 843 & 1009 \\
\hline & 767 & 529 \\
\hline & 729 & 90 \\
\hline & 691 & 70 \\
\hline & 650 & 65 \\
\hline & 563 & 60 \\
\hline & 520 & 35 \\
\hline & 153 & - \\
\hline$A / \mathrm{s}^{-1}$ & & $2.2 \times 10^{17}$ \\
\hline$E_{0} / \mathrm{kJ} \mathrm{mol}^{-1}$ & & 259 \\
\hline$Z_{\mathrm{Lj}} / 10^{-10} \mathrm{~cm}^{3}$ molecule ${ }^{-1} \mathrm{~s}^{-1}$ & & 4.25 \\
\hline
\end{tabular}

Table 5 Temperature dependent transition state parameters for RRKM calculations for the decomposition of 3-thia-2,4-dioxasiletane

\begin{tabular}{|c|c|c|c|c|c|}
\hline & \multicolumn{5}{|l|}{$T / \mathrm{K}$} \\
\hline & 297 & 341 & 409 & 479 & 609 \\
\hline \multirow[t]{5}{*}{ TS wavenumbers $/ \mathrm{cm}^{-1}$} & 90 & 90 & 100 & 120 & $\overline{140}$ \\
\hline & 70 & 85 & 95 & 110 & 130 \\
\hline & 65 & 70 & 85 & 95 & 125 \\
\hline & 60 & 68 & 85 & 90 & 105 \\
\hline & 35 & 38 & 42 & 49 & 61 \\
\hline$Z_{\mathrm{LJ}}\left(\mathrm{SF}_{6}\right) / 10^{-10} \mathrm{~cm}^{3}$ molecule ${ }^{-1} \mathrm{~s}^{-1}$ & 4.25 & 4.34 & 4.47 & 4.60 & 4.83 \\
\hline
\end{tabular}

where the calculated rate coefficients can be readily compared with the experimental values.

\section{Discussion}

\section{General comments and rate constant comparisons}

The main experimental purpose of this study was to measure the rate coefficients and their temperature dependence for the reaction of $\mathrm{SiH}_{2}$ with $\mathrm{SO}_{2}$. This has been accomplished. It is important to note that despite the known photodecomposition of $\mathrm{SO}_{2}$ at $193 \mathrm{~nm},{ }^{19}$ under our conditions it was insufficient to interfere with the $\mathrm{SiH}_{2}$ decay kinetics. There are no previous measurements of rate coefficients or Arrhenius parameters for this reaction. Other comparisons are, however, possible. Table 6 shows the Arrhenius parameters for this system alongside those of reactions of $\mathrm{SiH}_{2}$ with other O-atom containing molecules, both organic and inorganic. ${ }^{10-13,26-33}$ It is assumed that in the reaction studied here, the Arrhenius parameters at $1.3 \mathrm{kPa}$ are close enough to those at infinite pressure, to make no significant difference. Some of the other reactions are much more pressure dependent and where necessary rate coefficients have been extrapolated to obtain their true second order (infinite pressure) values. In these cases there is greater uncertainty associated with the Arrhenius parameters. In the examples listed there is some spread in values of $A$ and $E_{\mathrm{a}}$ but most lie within fairly tight ranges: -10 to -12 for $\log \left(A / \mathrm{cm}^{3}\right.$ molecul $\left.{ }^{-1} \mathrm{~s}^{-1}\right)$ and -1.6 to -6.2 for $\left(E_{\mathrm{a}} / \mathrm{kJ} \mathrm{mol}^{-1}\right)$. The significant exception to this is the reaction of $\mathrm{SiH}_{2}+\mathrm{CO}_{2}$. The closest similarity of parameters occurs between those of the present study and the reactions with carbonyl compounds (apart from $\mathrm{SiH}_{2}+\mathrm{CO}_{2}$ ). Another worthwhile

Table 6 Comparison of Arrhenius parameters for addition reactions of silylene to carbonyl and related species

\begin{tabular}{llll}
\hline Reactants & $\log A^{a}$ & $E_{\mathrm{a}} / \mathrm{kJ} \mathrm{mol}^{-1}$ & Ref. \\
\hline $\mathrm{SiH}_{2}+\mathrm{SO}_{2}$ & $-10.10 \pm 0.06$ & $-3.45 \pm 0.46$ & This work \\
$\mathrm{SiH}_{2}+\mathrm{CO}_{2}$ & $-11.89 \pm 0.13$ & $+16.4 \pm 1.2$ & 13 \\
$\mathrm{SiH}_{2}+\mathrm{CO}^{b}$ & -9.99 & -3.0 & 12 \\
$\mathrm{SiH}_{2}+\mathrm{CH}_{3} \mathrm{CHO}^{b}$ & $-10.10 \pm 0.06$ & $-3.9 \pm 0.5$ & 11 \\
$\mathrm{SiH}_{2}+\left(\mathrm{CH}_{3}\right)_{2} \mathrm{CO}$ & $-10.17 \pm 0.04$ & $-4.5 \pm 0.3$ & 10 \\
$\mathrm{SiH}_{2}+\mathrm{O}_{2}$ & $-11.08 \pm 0.04$ & $-1.57 \pm 0.9$ & 26 \\
$\mathrm{SiH}_{2}+\mathrm{NO}^{b}$ & $-11.66 \pm 0.01$ & $-6.20 \pm 0.10$ & 27 \\
$\mathrm{SiH}_{2}+\mathrm{N}_{2} \mathrm{O}$ & $-12.09 \pm 0.04$ & $-2.0 \pm 0.3$ & 28 \\
$\mathrm{SiH}_{2}+\mathrm{THF}^{b}$ & $-10.59 \pm 0.10$ & $-5.76 \pm 0.65$ & 29 \\
${ }^{a} \mathrm{Units}_{\text {: }} \mathrm{cm}^{3}$ molecule & & & \\
obtained by extrapolation to infinite pressure. &
\end{tabular}


Table 7 Comparison of Lennard-Jones collision efficiencies for reactions of $\mathrm{SiH}_{2}$ with O-atom containing molecules at $298 \mathrm{~K}^{a}$

\begin{tabular}{lclc}
\hline Reactants & $k^{b}$ & $Z_{\mathrm{LJ}}{ }^{b}$ & Efficiency/\% \\
\hline $\mathrm{SiH}_{2}+\mathrm{SO}_{2}$ & 3.15 & 4.41 & 71 \\
$\mathrm{SiH}_{2}+\mathrm{CO}_{2}$ & $<4.2 \times 10^{-5}$ & 4.10 & $<0.00102$ \\
$\mathrm{SiH}_{2}+\mathrm{CO}^{c}$ & 3.43 & 3.80 & 90 \\
$\mathrm{SiH}_{2}+\mathrm{CH}_{3} \mathrm{CHO}^{c}$ & 4.0 & 5.39 & 74 \\
$\mathrm{SiH}_{2}+\left(\mathrm{CH}_{3}\right)_{2} \mathrm{CO}$ & 4.2 & 5.54 & 76 \\
$\mathrm{SiH}_{2}+\mathrm{O}_{2}$ & 0.164 & 3.55 & 4.6 \\
$\mathrm{SiH}_{2}+\mathrm{NO}^{c}$ & 4.6 & 3.68 & 125 \\
$\mathrm{SiH}_{2}+\mathrm{N}_{2} \mathrm{O}$ & 0.019 & 4.12 & 0.46 \\
$\mathrm{SiH}_{2}+\mathrm{THF}^{c}$ & 2.8 & 5.2 & 45
\end{tabular}

${ }^{a}$ For references see Table $6 .{ }^{b}$ Units: $10^{-10} \mathrm{~cm}^{3}$ molecule ${ }^{-1} \mathrm{~s}^{-1} \cdot{ }^{c}$ Pressure dependent reaction; parameters obtained by extrapolation to infinite pressure.

comparison is that of the collision efficiencies of these reactions. Table 7 shows the $298 \mathrm{~K}$ values of the rate coefficients of these reactions and their calculated Lennard-Jones collision numbers. The ratios of these quantities give the collision efficiencies (expressed as percentages in the table). High efficiencies (70-90\%) characterise both the current reaction ${ }^{34}$ and those of reactions of $\mathrm{SiH}_{2}$ with the carbonyl containing species (apart from $\mathrm{CO}_{2}$ ). The reasons for the low value efficiencies have been discussed in detail in our earlier review $^{6}$ and this is not repeated here. The high value efficiencies reflect the electrophilic nature of silylene combined with the easily accessibility lone pairs of electrons which result in a donor-acceptor interaction and facilitate the formation of an intermediate. One other factor which is important is that the resulting species must be capable of further reaction to an ultimately stable product (or products) without requiring a high (secondary) energy barrier. ${ }^{6}$ It is this latter limitation which causes the $\mathrm{SiH}_{2}+\mathrm{CO}_{2}$ reaction to have an overall positive activation and low collisional efficiency. The reaction of $\mathrm{SiH}_{2}$ with $\mathrm{SO}_{2}$ is clearly different. The explanation for this is considered in the next section.

\section{The potential energy surface: comparisons with other systems}

There has been no previous calculation of the potential energy surface for the $\mathrm{SiH}_{2}+\mathrm{SO}_{2}$ reaction system with which to compare the results of the present work. However it is interesting to note that in the first step of the reaction the initial interaction of $\mathrm{SiH}_{2}$ is with the O-rather than the S-atom. This contrasts with reactions of atoms (such as $\mathrm{H}$ ) and radicals (such as $\mathrm{OH}$ and $\mathrm{CH}_{3}$ ) where initial interaction at the S-atom appears to be favoured. ${ }^{35}$ Of course $\mathrm{SiH}_{2}$ has an empty p orbital rather than an unpaired electron, and so this comparison may not be particularly illuminating. Unfortunately there is no published study of the reaction ${ }^{1} \mathrm{CH}_{2}+\mathrm{SO}_{2}$ with which to draw comparisons.

The energy surface found here shows a considerable complexity. It provides a lot of detailed information about possible intermediates in this reaction but it does not indicate a clearly defined mechanistic pathway. The main issue of contention seems to be whether the lowest enthalpy addition product viz. the four-membered ring, 3-thia-2,4-dioxa-siletane is sufficiently stable to be the main reaction product. This is dealt with in the next section. Clearly the higher enthalpy three membered thione-siloxirane ring is not likely to be a final product, since it is formed with considerable excess energy, well above the relatively low enthalpy transition state, TS2 $\left(-96 \mathrm{~kJ} \mathrm{~mol}^{-1}\right)$, for isomerisation to the more stable 3-thia-2,4-dioxa-siletane.

To provide some further insight we compare the surface to that for the reaction of $\mathrm{SiH}_{2}+\mathrm{CO}_{2}$. Most of the species on the this latter surface have been calculated and published by us, ${ }^{13}$ but one essential species, 3-sila-2,4-dioxa-cyclobutylidene together with its transition state for formation, not identified previously, have been added here to enable a more illuminating comparison. Details of this are given in the ESI. $†$ The essential parts of the two surfaces are shown in Fig. 8. It should be noted that loosely bound complexes have been omitted for simplification. This does not affect any conclusions. Several differences are worth pointing out. First the reaction of $\mathrm{SiH}_{2}$ with $\mathrm{SO}_{2}$ is barrierless, whereas that with $\mathrm{CO}_{2}$ has two barriers, a low one to form the 3-membered siloxirane ring but a high one to form the 4-membered 3-sila-2,4-dioxa-cyclobutylidene ring. The latter process cannot compete, which shows why this product cannot be formed from $\mathrm{SiH}_{2}+\mathrm{CO}_{2}$. In the $\mathrm{SiH}_{2}+\mathrm{SO}_{2}$ reaction, probably the extra size and availability of $\mathrm{d}$ orbitals in the sulfur atom, make the bridging structure of the transition state for thione-siloxirane ring formation lower in energy than its carbon counterpart. In the sulfur case, the four-membered ring is not formed directly, but comes from the 3-membered ring. Such a pathway does not exist in the $\mathrm{SiH}_{2}+\mathrm{CO}_{2}$ reaction, possibly because the dissociation process to $\mathrm{SiH}_{2} \mathrm{O}+\mathrm{CO}$ has such a low barrier, making other pathways uncompetitive. The direct pathway from $\mathrm{SiH}_{2}+\mathrm{CO}_{2}$ to 3-sila-2,4-dioxa-cyclobutylidene probably owes its high barrier to the need to bend and break the highly stable $\pi$ system of the $\mathrm{C}=\mathrm{O}$ double bonds, and maybe also the lack of $\mathrm{d}$ orbital participation. The relative stabilities of $\pi$ systems of the $\mathrm{C}=\mathrm{O}$ and $\mathrm{S}=\mathrm{O}$ double bonds can also be surmised as contributing to the significantly different exothermicities of formation of the 3-membered rings from their reactants, viz. siloxirone $\left(-78 \mathrm{~kJ} \mathrm{~mol}^{-1}\right)$ compared to thione-siloxirane $\left(-180 \mathrm{~kJ} \mathrm{~mol}^{-1}\right)$. For the 4 -membered rings the exothermicity difference is even greater, viz. 3-sila-2,4-dioxacyclobutylidene $\left(-68 \mathrm{~kJ} \mathrm{~mol}^{-1}\right)$ compared to 3-thia-2,4-dioxasiletane $\left(-265 \mathrm{~kJ} \mathrm{~mol}^{-1}\right)$. As well as the loss of $\pi$-bonds which occurs on formation of these rings there is a formal valency change from 4 to 2 for the carbon or sulfur atoms involved. For sulfur, this is no problem: valence state 2 is its favoured state for bonding, but for carbon, valence state 2 is that of a carbene a rather unstable state of bonding (although the two bonded O-atoms doubtless contribute to its preferred existence as a singlet rather than triplet state). The final point to note concerns the dissociation products of the 3-membered rings. Both reactions produce silanone. In the carbon case this is accompanied by carbon monoxide with its stable triple bond, whereas in the sulfur case sulfur monoxide is only double bonded. Moreover if spin is conserved, sulfur monoxide is produced in an excited rather than its ground state. This accounts for the large difference in dissociation energies of these three membered rings.

As a further check on the accuracy of the calculations carried out here we have compared the computed thermochemistry of some of the overall processes forming possible end products 

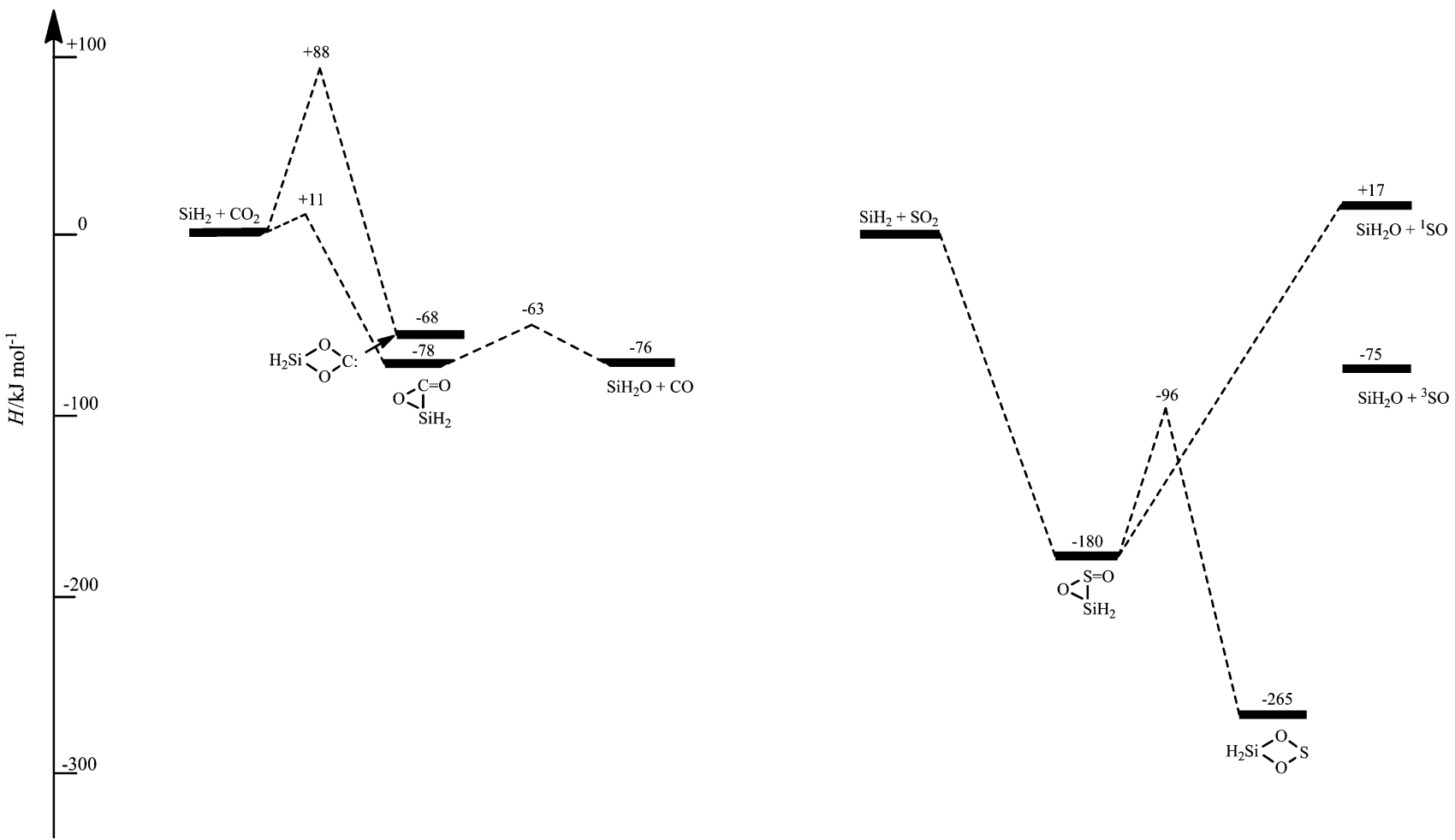

Fig. 8 Comparison of selected portions of the PE surfaces ( $\mathrm{G} 3$ level) of $\mathrm{SiH}_{2}+\mathrm{CO}_{2}$ and $\mathrm{SiH}_{2}+\mathrm{SO}_{2}$.

with estimates made from previous work, part experimental, part theoretical. This is shown in Table 8. The literature estimates for $\Delta H^{0}$ shown in this table are obtained by combining preferred values for $\Delta H_{\mathrm{f}}^{0}$ of the individual species, shown in Table 9 in the Appendix. Examination of Table 8 shows that the G3 values calculated here and the literature values differ by no more than $12 \mathrm{~kJ} \mathrm{~mol}^{-1}$. The G3 method is reliable to within ca. $\pm 4 \mathrm{~kJ} \mathrm{~mol}^{-1},{ }^{16}$ and most values agree within combined uncertainty limits.

\section{RRKM calculations and the reaction mechanism}

It is quite clear from Fig. 3 that the RRKM calculated pressure dependence for reaction (1), based on the assumption that it should correspond to that of the decomposition process of 3-thia-2,4-dioxa-siletane, reaction (1), is completely inconsistent with the experimental pressure dependence. The calculated pressure dependence implies that even if formed transiently,

Table 8 Comparison of overall reaction enthalpies $\left(\Delta H^{0} / \mathrm{kJ} \mathrm{mol}^{-1}\right)$ for end product formation in the $\mathrm{SiH}_{2}+\mathrm{SO}_{2}$ reaction

\begin{tabular}{lcr}
\hline Product & G3 enthalpy & \\
\hline $\mathrm{H}_{2} \mathrm{SiO}+{ }^{3} \mathrm{SO}$ & -75 & Literature $^{b}$ \\
$\mathrm{H}_{2} \mathrm{SiO}+{ }^{1} \mathrm{SO}$ & +17 & $-69 \pm 5$ \\
$\mathrm{SiO}_{2}+\mathrm{H}_{2} \mathrm{~S}$ & -284 & $+7 \pm 5$ \\
$\mathrm{HOSiO}+\mathrm{SH}$ & -158 & $-279 \pm 9$ \\
$\mathrm{HSiO}+\mathrm{HSO}$ & +23 & $-146 \pm 7$ \\
$\mathrm{HSiO}+\mathrm{HOS}$ & +41 & $+31 \pm 15$ \\
& & $+48 \pm 15$
\end{tabular}

${ }^{a}$ See Table $2 .^{b}$ See Table 9 (Appendix) for $\Delta H_{\mathrm{f}}^{0}$ values and refs for each species. 3-thia-2,4-dioxa-siletane would be too highly vibrationally excited to be stabilised to any extent, particularly at the lower pressures, and would mostly redissociate back to reactants. This rules out 3-thia-2,4-dioxa-siletane as the stable reaction end product. It is worth pointing out that the difference between calculated and observed pressure dependences is so large that any minor uncertainties in the input parameters for the RRKM calculation would make no significant difference. This RRKM calculation also rules out the formation of thione-siloxirane as the final product, since, even if it were to have been stabilised to the extent that no isomerisation via TS2 to 3-thia-2,4-dioxa-siletane had been possible, its energy well, at only $180 \mathrm{~kJ} \mathrm{~mol}^{-1}$ would not have allowed its stabilisation relative to redissociation back to reactants and so would have given rise to an even greater predicted pressure dependence than that calculated for 3-thia-2,4-dioxa-siletane.

These findings suggest a mechanism for this reaction in which an intermediate species is produced which cannot be stabilised but rather dissociates to yield the final products. If the three- or four-membered rings are formed at all they can only be in highly vibrational states which revert to the intermediate which can dissociate. Furthermore this intermediate must dissociate sufficiently rapidly to avoid collisional stabilisation, otherwise it would give rise to a pressure dependence. The very small effect observed experimentally does not suggest this (but see below). We have shown in these calculations: that product pairs, $\mathrm{HSiO}+\mathrm{HOS}, \mathrm{HSiO}+\mathrm{HSO}, \mathrm{H}_{2} \mathrm{Si}=\mathrm{O}+$ ${ }^{1} \mathrm{SO}$ can be ruled out because their formation is endothermic; that the product pair $\mathrm{SiO}_{2}+\mathrm{H}_{2} \mathrm{~S}$ can be ruled out because its formation requires a positive enthalpy barrier; that formation 
Table 9 Enthalpies of formation, $\Delta H_{\mathrm{f}}^{0} / \mathrm{kJ} \mathrm{mol}^{-1}$ : values and sources

\begin{tabular}{|c|c|c|}
\hline Species & $\Delta H_{\mathrm{f}}^{0}(298 \mathrm{~K})$ & Ref. \\
\hline $\mathrm{SiH}_{2}$ & $273 \pm 2$ & 38 \\
\hline $\mathrm{SO}_{2}$ & $-296.8 \pm 0.2$ & 39 \\
\hline \multirow[t]{5}{*}{$\mathrm{H}_{2} \mathrm{Si}=\mathrm{O}$} & $-98 \pm 8$ & 40 \\
\hline & $-98 \pm 4$ & 41 \\
\hline & -98.2 & 42 \\
\hline & $-92 \pm 20$ & 38 \\
\hline & $-98 \pm 4$ & Preferred \\
\hline \multirow[t]{4}{*}{$\mathrm{HSi}=\mathrm{O}$} & $36 \pm 8$ & 40 \\
\hline & $30 \pm 15$ & 41 \\
\hline & 28.8 & 42 \\
\hline & $30 \pm 15$ & Preferred \\
\hline \multirow[t]{3}{*}{$\mathrm{HOSi}=\mathrm{O}$} & $-312.5 \pm 6$ & 41 \\
\hline & -313.5 & 42 \\
\hline & $-313 \pm 6$ & Preferred \\
\hline \multirow[t]{4}{*}{$\mathrm{SiO}_{2}$} & $-282 \pm 9$ & 41 \\
\hline & -288 & 42 \\
\hline & $-305.4 \pm 33.5$ & 39 \\
\hline & $-282 \pm 9$ & Preferred \\
\hline${ }^{3} \mathrm{SO}$ & $5.0 \pm 1.3$ & 39 \\
\hline${ }^{1} \mathrm{SO}$ & $81.0 \pm 1.3$ & 39 \\
\hline $\mathrm{H}_{2} \mathrm{~S}$ & $-20.5 \pm 0.8$ & 39 \\
\hline \multirow[t]{6}{*}{$\mathrm{SH}$} & $139.3 \pm 5$ & 39 \\
\hline & $143 \pm 3$ & 43 \\
\hline & $141.87 \pm 0.52$ & 44 \\
\hline & $142.95 \pm 0.78$ & 45 \\
\hline & $143.4 \pm 1.9$ & 46 \\
\hline & $143 \pm 2$ & Preferred \\
\hline \multirow[t]{4}{*}{ HOS } & $18 \pm 15$ & 43 \\
\hline & $-21 \pm 42$ & 44 \\
\hline & $-5.3 \pm 2.3$ & 46 \\
\hline & $-5.3 \pm 2.3$ & Preferred \\
\hline \multirow[t]{5}{*}{ HSO } & $-4 \pm 3$ & 43 \\
\hline & $-4.8 \pm 7.3$ & 44 \\
\hline & $-6.1 \pm 2.9$ & 45 \\
\hline & $-22.6 \pm 2.3$ & 46 \\
\hline & $-22.6 \pm 2.3$ & Preferred \\
\hline
\end{tabular}

of $\mathrm{HOSi}=\mathrm{O}+\mathrm{SH}$ seems unlikely because of the required bonding reorganisation. This leaves $\mathrm{H}_{2} \mathrm{Si}=\mathrm{O}+{ }^{3} \mathrm{SO}$ as the only product pair both exothermic and with an apparently straightforward formation mechanism, although it requires an intersystem crossing to occur. Thus we suggest the following process as the best mechanistic description of this reaction:

$$
\mathrm{SiH}_{2}+\mathrm{SO}_{2} \rightarrow \mathrm{H}_{2} \mathrm{SiOSO}^{*} \rightarrow \mathrm{H}_{2} \mathrm{SiO}+{ }^{3} \mathrm{SO}
$$

The $\mathrm{H}_{2} \mathrm{SiOSO}$ intermediate could be the initial complex but we believe that it is more likely a vibrationally excited version of the adduct (i), because (i) is more stable. Moreover this adduct has the characteristics of a diradical; it can be formally written $\mathrm{H}_{2} \dot{\mathrm{S}} \mathrm{iOS}=\mathrm{O}$. This means that it has closely lying singlet and triplet states. ${ }^{36}$ Although we have not been able to obtain details of the triplet surface here by calculation, it seems to us that adduct (i) is a likely species where the necessary intersystem crossing could occur. Of course we cannot rule out that intersystem crossing might occur during the dissociation ${ }^{37}$ on the singlet surface at some intermediate stage of $\mathrm{O}-\mathrm{S}$ bond lengthening, nor also that it might occur from the $\mathrm{H}_{2} \mathrm{Si}=\mathrm{O}{ }^{1} \mathrm{~S}=\mathrm{O}$ complex itself, which is stable enough to be formed exothermically. Our experimental system does not allow us to detect either silanone or sulfur monoxide and so experimental confirmation of this mechanism must await further studies.

\section{Conclusion}

The reaction of silylene with sulfur dioxide in the gas phase is a fast process with no energy barrier, occurring at $71 \%$ of the maximum (collision) rate at $298 \mathrm{~K}$. The rate coefficients show little or no pressure dependence. The G3 calculated potential energy surface shows the presence of two stable low-energy cyclic molecules, but the lack of pressure dependence, predicted by RRKM theory, shows that these are not the end products. The most suitable candidates for these are $\mathrm{H}_{2} \mathrm{SiO}+{ }^{3} \mathrm{SO}$. The reaction contrasts strongly with that of $\mathrm{SiH}_{2}+\mathrm{CO}_{2}$, which is slow and has a positive activation energy. A comparison of the potential energy surfaces offers an explanation for these differences.

\section{Appendix}

Collected in Table 9 are the best literature values we have been able to find of $\Delta H_{\mathrm{f}}^{0}(298 \mathrm{~K})$ for the potential end product species of reaction of $\mathrm{SiH}_{2}$ and $\mathrm{SO}_{2}$, as well as the reactants. These values were used to obtain the reaction enthalpies cited in Table 8 of this paper.

We have not ourselves evaluated the complete literature for each value but instead relied as far as possible on previous data evaluations. ${ }^{38-46}$ Where, in our opinion, these are sufficiently reliable we have chosen a single value. Where we were less certain we have cited several values and made the best choice we could. For the oxy-silicon species $\left(\mathrm{H}_{2} \mathrm{Si}=\mathrm{O}, \mathrm{HSi}=\mathrm{O}, \mathrm{HOSi}=\mathrm{O}\right.$ and $\left.\mathrm{SiO}_{2}\right)$ only theoretical values exist. ${ }^{38,40-42}$ There is a need for experimental values in this area, difficult though they may be to obtain. For the species HOS and HSO, we have taken the latest theoretical calculations of Nagy et $a{ }^{46}$ This paper attempts to evaluate previous literature, although there remain serious discrepancies between theory and experiment.

\section{Acknowledgements}

R.B. thanks the Ministerio de Economia y Competitividad for support under Project CTQ2010-16402 and Royal Society of Chemistry for a journals grant. N.G. thanks Dow Corning for the financial support of a studentship.

\section{References}

1 (a) P. P. Gaspar, in Reactive intermediates, ed. M. Jones Jr. and R. A. Moss, Willey-Interscience, N.Y., 1978, vol. 1, p. 229; (b) P. P. Gaspar, in Reactive intermediates, ed. M. Jones Jr. and R. A. Moss, Wiley-Interscience, N.Y., 1981, vol. 2, p. 335; (c) P. P. Gaspar, in Reactive intermediates, ed. M. Jones Jr. and R. A. Moss, Willey-Interscience, N.Y., 1985, vol. 3, p. 333.

2 P. P. Gaspar and R. West, in The Chemistry of Organosilicon Compounds, ed. Z. Rappoport and Y. Apeloig, Wiley, Chichester, 1998, ch. 43, vol. 2, p. 2463.

$3 \mathrm{~N}$. Tokitoh and W. Ando, in Reactive Intermediate Chemistry, ed. R. A. Moss, M. S. Platz and M. Jones, Jr., Wiley \& Sons, NY, 2004, ch. 14, p. 651. 
4 R. Becerra and R. Walsh, Kinetics \& mechanisms of silylene reactions: A prototype for gas-phase acid/base chemistry, in Research in Chemical Kinetics, ed. R. G. Compton and G. M. Hancock, Elsevier, Amsterdam, 1995, vol. 3, p. 263.

5 J. M. Jasinski, R. Becerra and R. Walsh, Chem. Rev., 1995, 95, 1203.

6 R. Becerra and R. Walsh, Phys. Chem. Chem. Phys., 2007, 9, 2817.

7 R. Becerra and R. Walsh, Dalton Trans., 2010, 39, 9217.

8 (a) A. G. Moiseev and W. J. Leigh, J. Am. Chem. Soc., 2006, 128, 14442; (b) A. G. Moiseev and W. J. Leigh, Organometallics, 2007, 26, 6268; (c) A. G. Moiseev and W. J. Leigh, Organometallics, 2007, 26, 6277; (d) A. G. Moiseev, E. Coulais and W. J. Leigh, Chem.-Eur. J., 2009, 15, 8485; (e) W. J. Leigh, S. S. Kostina, A. Bhattacharya and A. G. Moiseev, Organometallics, 2010, 29, 662; $(f)$ W. J. Leigh, S. S. Kostina, A. Bhattacharya and A. G. Moiseev, Organometallics, 2010, 29, 662; $(g)$ S. S. Kostina and W. J. Leigh, J. Am. Chem. Soc., 2011, 133, 4377; (h) S. S. Kostina, T. Singh and W. J. Leigh, Organometallics, 2012, 31, 3755.

9 (a) Y. Mizubhata, T. Sasamori and N. Tokitoh, Chem. Rev., 2009, 109, 3479; (b) M. Kira, Dalton Trans., 2010, 39, 9175; (c) V. Y. Lee and A. Sekiguchi, Heavy analogs of carbenes: Silylenes, Germylenes, Stannylenes and Plumbylenes, in Organometallic compounds of low coordinate Si, Ge, Sn and $\mathrm{Pb}$ : from Phantom species to stable compounds, Wiley, Chichester, 2010, ch. 4, p. 139; (d) M. Asay, C. Jones and M. Driess, Chem. Rev., 2011, 111, 354; (e) S. G. Ghadwal, R. Azhakar and H. W. Roesky, Acc. Chem. Res., 2013, 46, 444.

10 R. Becerra, J. P. Cannady and R. Walsh, J. Phys. Chem. A, 1999, 103, 4457.

11 R. Becerra, J. P. Cannady and R. Walsh, Phys. Chem. Chem. Phys., 2001, 3, 2343.

12 R. Becerra, J. P. Cannady and R. Walsh, J. Phys. Chem. A, 2001, 105, 1897.

13 R. Becerra, J. P. Cannady and R. Walsh, J. Phys. Chem. A, 2002, 106, 4922.

14 J. M. Jasinski and J. O. Chu, J. Chem. Phys., 1988, 88, 1678.

15 M. J. Frisch, G. W. Trucks, H. B. Schlegel, G. E. Scuseria, M. A. Robb, J. R. Cheeseman, J. A. Montgomery, Jr., T. Vreven, K. N. Kudin, J. C. Burant, J. M. Millam, S. S. Iyengar, J. Tomasi, V. Barone, B. Mennucci, M. Cossi, G. Scalmani, N. Rega, G. A. Petersson, H. Nakatsuji, M. Hada, M. Ehara, K. Toyota, R. Fukuda, J. Hasegawa, M. Ishida, T. Nakajima, Y. Honda, O. Kitao, H. Nakai, M. Klene, X. Li, J. E. Knox, H. P. Hratchian, J. B. Cross, V. Bakken, C. Adamo, J. Jaramillo, R. Gomperts, R. E. Stratmann, O. Yazyev, A. J. Austin, R. Cammi, C. Pomelli, J. W. Ochterski, P. Y. Ayala, K. Morokuma, G. A. Voth, P. Salvador, J. J. Dannemberg, V. G. Zakrzewski, S. Dapprich, A. D. Daniels, M. C. Strain, O. Farkas, D. K. Malick, A. D. Rabuck, K. Raghavachari, J. B. Foresman, J. V. Ortiz, Q. Cui, A. G. Baboul, S. Clifford, J. Cioslowski, B. B. Stefanov, G. Liu, A. Liashenko, P. Piskorz, R. Komaromi, R. L. Martin, D. J. Fox, T. Keith, M. A. Al-Laham, C. Y. Peng, A. Nanayakkara, M. Challacombe,
P. M. W. Gill, B. Johnson, W. Chen, M. W. Wong, C. Gonzales and J. A. Pople, Gaussian 03, revision E.01, Gaussian, Inc., Wallingford, CT, 2004.

16 L. A. Curtiss, K. Raghavachari, P. C. Redfern, V. Rassolov and J. A. Pople, J. Chem. Phys., 1998, 109, 7764.

17 C. Gonzales and H. B. Schlegel, J. Chem. Phys., 1989, 90, 2154.

18 (a) J. A. Pople, A. P. Scott, M. W. Wong and L. Radom, Isr. J. Chem., 1993, 33, 345; (b) J. M. Merrick, D. Moran and L. Radom, J. Phys. Chem. A, 2007, 111, 11683.

19 H. Okabe, Photochemistry of Small Molecules, WileyInterscience, 1978, pp. 247-256.

20 For sulphur monoxide, SO, the lowest two electronic states are $\tilde{X},{ }^{3} \Sigma^{-}$and $\tilde{A},{ }^{1} \Delta$. We use the simpler designations ${ }^{3} \mathrm{SO}$ and ${ }^{1} \mathrm{SO}$ throughout this paper.

21 (a) R. Becerra and R. Walsh, Int. J. Chem. Kinet., 1994, 26, 45; (b) R. Becerra, J. P. Cannady, G. Dormer and R. Walsh, J. Phys. Chem. A, 2008, 112, 8665.

22 (a) N. Al-Rubaiey and R. Walsh, J. Phys. Chem., 1994, 98, 5303; (b) N. Al-Rubaiey, R. Becerra and R. Walsh, Phys. Chem. Chem. Phys., 2002, 4, 5072.

23 K. A. Holbrook, M. J. Pilling and S. H. Robertson, Unimolecular Reactions, Wiley, Chichester, 2nd edn, 1996.

24 Care has to be exercised in the use of this equation because $A_{1}$ is usually expressed in concentration units and $\Delta S_{-1,1}^{0}$ employs values based on the standard state of 1 bar. See ESI $\dagger$.

25 H. Hippler and J. Troe, in Advances in Gas Phase Photochemistry and Kinetics, ed. M. N. R. Ashfold and J. E. Baggott, Royal Society of Chemistry, London, 1989, ch. 5, vol. 2, p. 209.

26 R. Becerra, S.-J. Bowes, J. S. Ogden, J. P. Cannady, I. Adamovic, M. S. Gordon, M. J. Almond and R. Walsh, Phys. Chem. Chem. Phys., 2005, 7, 2900.

27 R. Becerra, S.-J. Bowes, J. S. Ogden, J. P. Cannady, M. J. Almond and R. Walsh, J. Phys. Chem. A, 2005, 105, 1071.

28 R. Becerra, H. M. Frey, B. P. Mason and R. Walsh, Chem. Phys. Lett., 1991, 185, 415.

29 R. Becerra, J. P. Cannady, O. Goulder and R. Walsh, J. Phys. Chem. A, 2010, 114, 784.

30 Omitted from Table 6 and also Table 7, are the reactions of $\mathrm{SiH}_{2}$ with alcohols ${ }^{31,32}$ and most ethers. ${ }^{29,33}$ This is because these reactions, although rapid and efficient, are less closely mechanistically related to the present reaction.

31 U. N. Alexander, K. D. King and W. D. Lawrance, J. Phys. Chem. A, 2002, 106, 973.

32 R. Becerra, J. P. Cannady and R. Walsh, J. Phys. Chem. A, 2011, 115, 4231.

33 (a) R. Becerra, I. W. Carpenter, G. J. Gutsche, K. D. King, W. D. Lawrance, W. S. Staker and R. Walsh, Chem. Phys. Lett., 2001, 333, 83; (b) U. N. Alexander, K. D. King and W. D. Lawrance, Phys. Chem. Chem. Phys., 2001, 3, 3085.

34 It is again assumed that the rate constant at $1.3 \mathrm{kPa}$ is close enough to the high pressure limiting value not to make any significant difference.

35 (a) B. J. Ratliff, X. Tang, L. J. Butler, D. E. Szpunar and K.-Ch. Lau, J. Chem. Phys., 2009, 131, 044304; (b) B. W. Alligood, B. L. FitzPatrick, E. J. Glassman, L. J. Butler and 
K.-Ch. Lau, J. Chem. Phys., 2009, 131, 044305; (c) J. D. Garrido, M. Y. Ballester, Y. Orozco-Gonzalez and S. Canuto, J. Phys. Chem., 2011, 115, 1453; (d) S. Sitha, L. L. Jewell, S. J. Piketh and G. Fourie, Atmos. Environ., 2011, 45, 745.

36 The same would apply to adduct(ii), since adduct(i) and adduct(ii) are merely different conformers of the same diradical.

37 It is possible that such a process could be slightly energy dependent and thereby give rise to the small pressure dependence observed in this reaction.

38 R. Becerra and R. Walsh, in The Chemistry of Organosilicon Compounds, ed. Z. Rappoport and Y. Apeloig, Wiley, Chichester, 1998, ch. 4, vol. 1, p. 153.

39 M. W. Chase Jr., NIST-JANAF Thermochemical tables, J. Phys. Chem. Ref. Data, Monograph No. 9, American Institute of Physics, Melville, NY, 4th edn, 1998.

40 C. L. Darling and H. B. Schlegel, J. Phys. Chem., 1993, 97, 8207.

41 M. D. Allendorf, C. F. Melius, P. Ho and M. R. Zachariah, J. Phys. Chem., 1995, 99, 15285.
42 M. R. Zachariah and W. Tsang, J. Phys. Chem., 1995, 99, 5308.

43 A. J. Hynes and P. H. Wine, in Gas Phase Combustion Chemistry, ed. W. C. Gardiner Jr., Springer-Verlag, Inc., N.Y., 2000, ch. 3, p. 343.

44 A. Burcat and B. Ruscic, Third Millenium Ideal Gas and Condensed Phase. Thermochemical Database for Combustion with Updates from Active Thermochemical Tables, TechnionIIT, Aerospace Engineering and Argonne National Laboratory, Chemistry Division, 2005.

45 S. P. Sanders, R. R. Friedl, A. R. Ravishankara, D. M. Golden, C. E. Kolb, M. J. Kurylo, M. J. Molina, G. K. Moortgat, H. Keller-Rudek, B. J. Finlayson-Pitts, P. H. Wine, R. E. Huie and V. L. Orkin, Chemical Kinetics and Photochemical Data for Use in Atmospheric Studies, Evaluation Number 15, NASA Jet Propulsion Laboratory Publication, California Institute of Technology, Pasadena, CA, 2006.

46 B. Nagy, P. Szakacs, J. Csontos, Z. Rolik, G. Tasi and M. Kallay, J. Phys. Chem. A, 2011, 115, 7823. 